\title{
Systematic review of knowledge, attitude, and practices regarding dengue in Malaysia
}

\author{
Lamidi-Sarumoh Alaba Ajibola ${ }^{1,3}$, Shamarina Shohaimi ${ }^{1,2^{*}}$, Mohd Bakri Adam², Mohd Noor Hisham Mohd Nadzir ${ }^{1}$, Oguntade \\ Emmanuel Segun ${ }^{2}$ \\ ${ }^{1}$ Department of Biology, Faculty of Science, Universiti Putra Malaysia, Serdang, Malaysia. \\ ${ }^{2}$ Institute for Mathematical Research, Universiti Putra Malaysia, Serdang, Malaysia. \\ ${ }^{3}$ Department of Mathematics, Faculty of Science, Gombe State University, Tundun Wada, Nigeria.
}

\begin{tabular}{lll}
\hline ARTICLE INFO & & ABSTRACT \\
\cline { 1 - 1 } $\begin{array}{l}\text { Received on: 09/09/2018 } \\
\text { Accepted on: 11/11/2018 }\end{array}$ & $\begin{array}{l}\text { Several studies had focused on assessing the relationship and description of the level of knowledge, attitude, and } \\
\text { preventive practices (KAP) regarding dengue in Malaysia among different districts, different set of people living } \\
\text { in rural, semi-urban, and urban areas over the years. This study reviewed the behavioral evidence, differences, and } \\
\text { similarities of the KAP studies despite the use of different instruments for data collection and methodologies for the } \\
\text { analysis of data. The search for the literature was conducted in January 2018 via the electronic database of PubMed, }\end{array}$ \\
$\begin{array}{ll}\text { Key words: } \\
\text { Knowledge, attitude, } \\
\text { practices, dengue, Malaysia. }\end{array}$ & $\begin{array}{l}\text { Scopus, Science Direct, EBSCOhost, ProQuest, and Google Scholar. Open access journals that were published } \\
\text { between June 1986 and December 2017 were examined, focusing mainly on Malaysia as a country. Seventeen articles } \\
\text { met the inclusion benchmarks. Most studies showed that the high level of knowledge influences good attitude and high } \\
\text { preventive practices. Knowledge was mostly attributed to some socio-demographic factors. It is essential to compile } \\
\text { the KAP studies regarding dengue which are done in different locations/districts of a country over the years, in order } \\
\text { to project into the future on how to disseminate information to mitigate dengue infection and also to know the most } \\
\text { influencing factors affecting it. }\end{array}$ \\
\hline
\end{tabular}

\section{INTRODUCTION}

Dengue fever (DF) is a viral infection that can be transmitted to human by the bite of infected Aedes mosquitoes and can also be transmitted to Aedes mosquitoes from a viremic human. Aedes species known to be transmitting the infection are Aedes aegypti and Aedes albopictus (Rudnick, 1965). DF is one of the major health concerns in Malaysia due to its seropositivity and seroprevalence among adults (Azami et al., 2011). DF can sometimes degenerate into dengue hemorrhagic fever (DHF) or dengue shock syndrome depending on the severity of the infection and the immunity of the viremic individual (Rothman, 2011). The fast expansion of the dengue virus is

\footnotetext{
${ }^{*}$ Corresponding Author

Shamarina Shohaimi, Department of Biology, Faculty of Science,

Universiti Putra Malaysia, Serdang, Malaysia.

E-mail: shamarina@upm.edu.my
}

expected to increase based on some factors, such as modern dynamics of climate change, globalization, urbanization, trades and travels, socioeconomic status, viral evolution, ecological disturbance, lack of effective vaccines, and no specific treatment (Gubler, 2011). The need to assess community health behavior in order to understand knowledge, attitude, and practice (KAP) on dengue viral infection and its vectors was necessitated because of the increasing folds of the diseases on yearly basis in Malaysia. From 2000 to 2014, dengue cases increased from 7,103 to 108,698 (Mudin, 2015). The annual incidence rate increased more than 11 folds (31.6-361.1 cases per 100,000 people). KAP survey on dengue is an approach used to know the extent and impact of health programs in a particular domain and how people of the domain were informed. KAP studies regarding dengue can also be used as a baseline to motivate community participation in preventing and curtailing the DF and DHF (Benthem et al., 2002). 
Climate change, ecology of dengue vectors and human behavior

Malaysia has a typical tropical climate which is characterized by hot, humid, and rainy season throughout the year. Generally, the weather in Malaysia is bimodal: the Southwest monsoon season; April to September and the Northeast monsoon season; October to March. Temperature, rainfall, and relative humidity have been established to be contributing factors influencing the ecology of dengue vectors (Naish et al., 2014). The complete life cycle of dengue vector involves both terrestrial and aquatic habitats. The mosquito eggs and the adult belong to the terrestrial habitat while pupa and the larva belong to the aquatic habitat. The larval developmental time, larval survival, and adult reproduction depend on the mean temperature to complete their life cycle either in a short period of time or a long period of time (Marinho et al., 2016). High temperature reduces the extrinsic incubation period (Ewing et al., 2016). Thus, an increase in the rate of reproduction and the rate of transmission. Increase in humidity aids dengue vectors as it increases their feeding activities, the rate of survival, and egg development (Gubler et al., 2001). The rainfall has a direct influence on dengue vectors by creating artificial breeding sites in trash cans, plastics, and potholes. The inverse effect of the rainfall decreases the eggs and adult mosquitoes through erosion (Naish et al., 2014). Human behavior also influences the increase of dengue vectors directly by daily practices, such as indiscriminate dumping of refuse, low level of sanitation, storage of water without cover, and lack of preventive practices. According to Hairi et al. (2003), storage of water among rural communities in Kuala Kangsar district, Malaysia was more of tradition and culture despite the availability of pipe-borne water. Human behavior is known to be one of the controllable factors affecting dengue but it is difficult to control (Mudin, 2015) because community participation and cooperation is needed for effective preventive practices against the spread of dengue infection.

\section{History of dengue and KAP studies in Malaysia}

The first discovery of DF in Malaysia was in 1901 in Penang (Poovaneswari, 1993) and it was documented in 1902 (Lam, 1994). It has since then been a disease of concern throughout the nation. The first report of DHF was in 1962 which had the reported morbidity rate of 41 cases and mortality rate of 5. In 1973, there was a major outbreak of DHF which affects almost every part of the country (Poovaneswari, 1993), 1,487 cases and 54 deaths were reported. In 1974, DF and DHF became notifiable diseases, 2,200 cases were reported and 10 deaths (Mudin, 2015). In 1975, Malaysia government came with a plan under the vector-borne diseases control program in the sixth Malaysia plan which includes four strategies; anti-larva measure, anti-adult mosquitos' measure; health education, and enforcement of Destruction of Diseases Bearing Insects Act 1975. This Act gave birth to the first KAP study in Malaysia which was written by Dobbins and Else (1975), a study conducted in an urban Malay village and all other subsequent KAP studies which were reviewed in this article. There were also major outbreaks of dengue in 1978, 1982, 1990, and 1991 (Hairi et al., 2003). In 1993, "Program Bebas Denggi" or Dengue
Free Program was introduced in Malaysian schools in order to inculcate the appropriate knowledge of dengue and preventive practices among the young generations.

\section{Analytic approach of KAP regarding dengue studies}

The exploration of the influence of risk factors of KAP studies regarding dengue may depend on the applicable instrument used for data collection from a particular population and the analytic approach. This study aimed to systematically review the relevant literature on KAP regarding dengue, focusing on Malaysia as a country; to converse the methodologies used; the structure of the instruments, and suggest future research direction. The rationale behind the aim of the review was to draw connection among the articles examined and also reveal the inconsistency of the instruments used for data collection. The KAP study of a particular area may differ from another area depending on education, experience, the location of the respondents, and exposure to information from mass media and social media. Methodology, instruments, and targeted population are also major elements influencing the results from KAP studies regarding dengue.

\section{METHODS}

\section{Exploration approach}

A literature search was conducted in January 2018 using the electronic databases of PubMed, Scopus, Science Direct, EBSCO host, ProQuest, and Google Scholar to obtain the information on KAP studies regarding dengue in Malaysia. The month and year of publications range from June 1986 to September 2017. The search was restricted to journal articles published in English language and open peer review with full-text. The five keywords used for the search were knowledge, attitude, practices, dengue, and Malaysia. The articles considered as part of the review were crosschecked through references and citations to ensure all relevant articles were included. Preferred reporting items for systematic reviews and meta-analysis (PRISMA) which had four-phase diagram flow was used for the exploration (Moher et al., 2010) as shown in Figure 1. Assessment of risk of bias for the articles reviewed was done using the Critical Appraisal Skill Program (CASP) (2014) for qualitative research with some modifications. Thus, evaluation of the strength and limitations of each article were established. The evaluation was done for both study and outcome level without consideration of data synthesis due to the difference in aims of the studies and results.

\section{Selection benchmarks}

The selected articles from the search results were considered based on three standards. First, for the purpose of substantial information, published articles that are easily accessible for peer reviews. Secondly, research studies that were solely done in Malaysia and its KAP regarding dengue. Finally, considerations were given to articles indicating the factors affecting KAP with the different statistical approach.

Words used interchangeably: Preventive practice and practices, occupational level and employment status, and participants and respondents. 

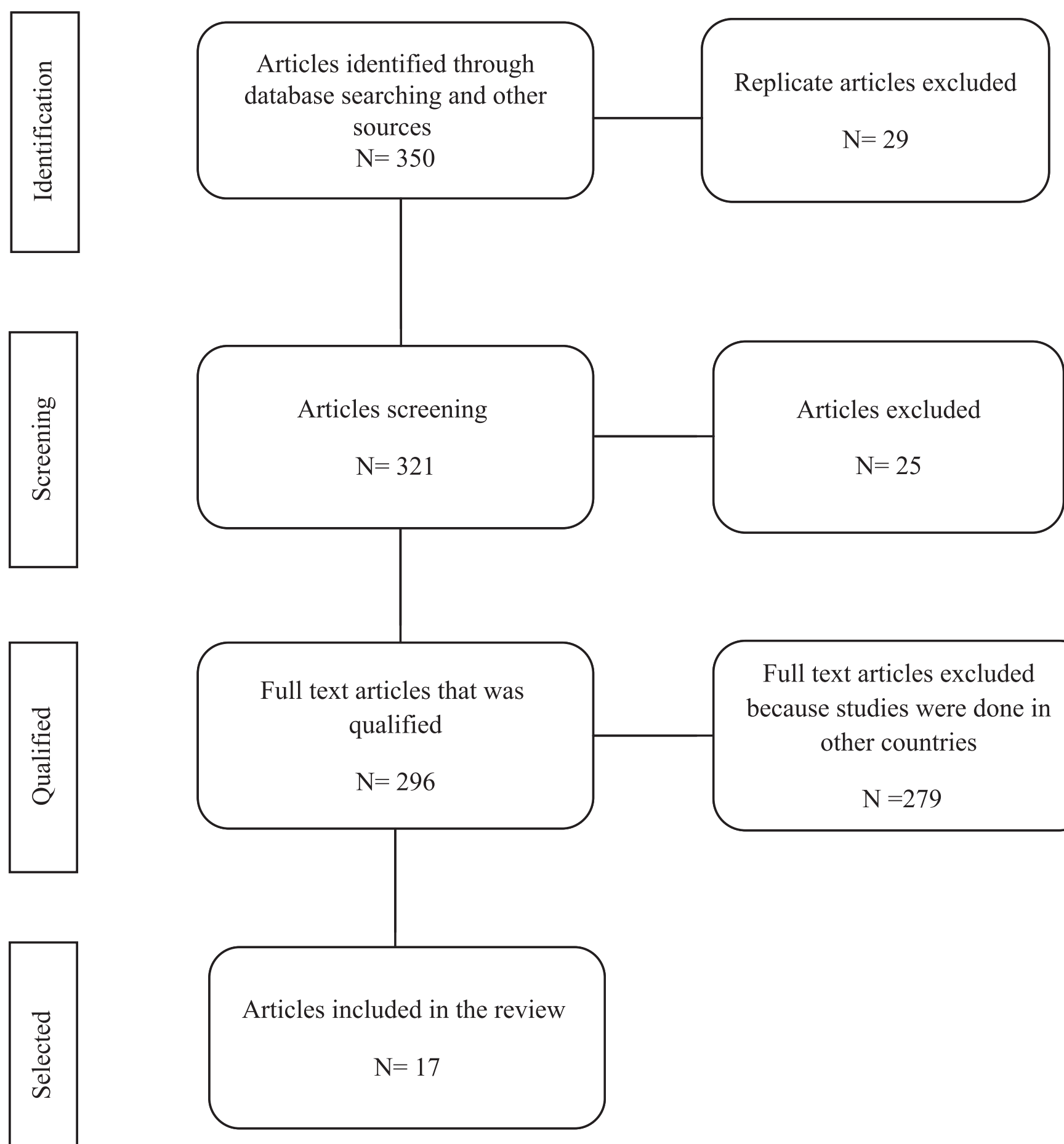

Full text articles excluded because studies were done in other countries

$\mathrm{N}=279$

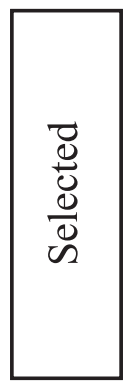

Figure 1. PRISMA flowchart of the literature search.

\section{RESULTS}

The exploration yields 321 studies without replicate and 296 of it were hypothetically appropriate. Further consideration of Malaysia as a country and perusal led to 17 studies strictly met the benchmark selection criteria. Table 1 shows the characteristics of the 17 studies of KAP regarding dengue in Malaysia.

\section{Analytical approaches}

All the selected articles were mostly cross-sectional studies. Descriptive statistics were used to summarize the sociodemographic variables and sources of information. Statistical significance of the different analytic approaches was considered at a $p$-value $<0.05$. Fifteen of the studies used combinations of different analytical methods, such as bivariate and multivariate 


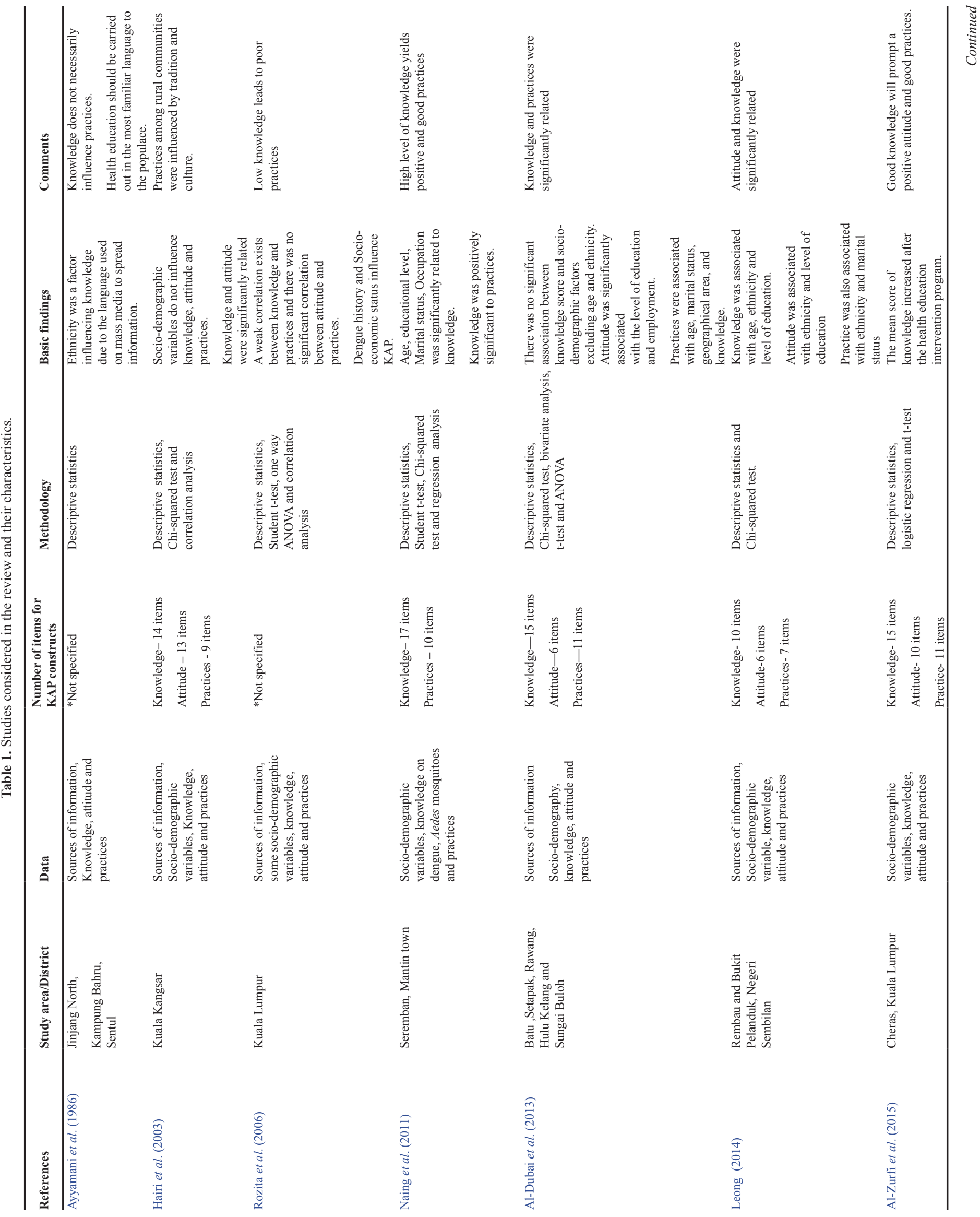




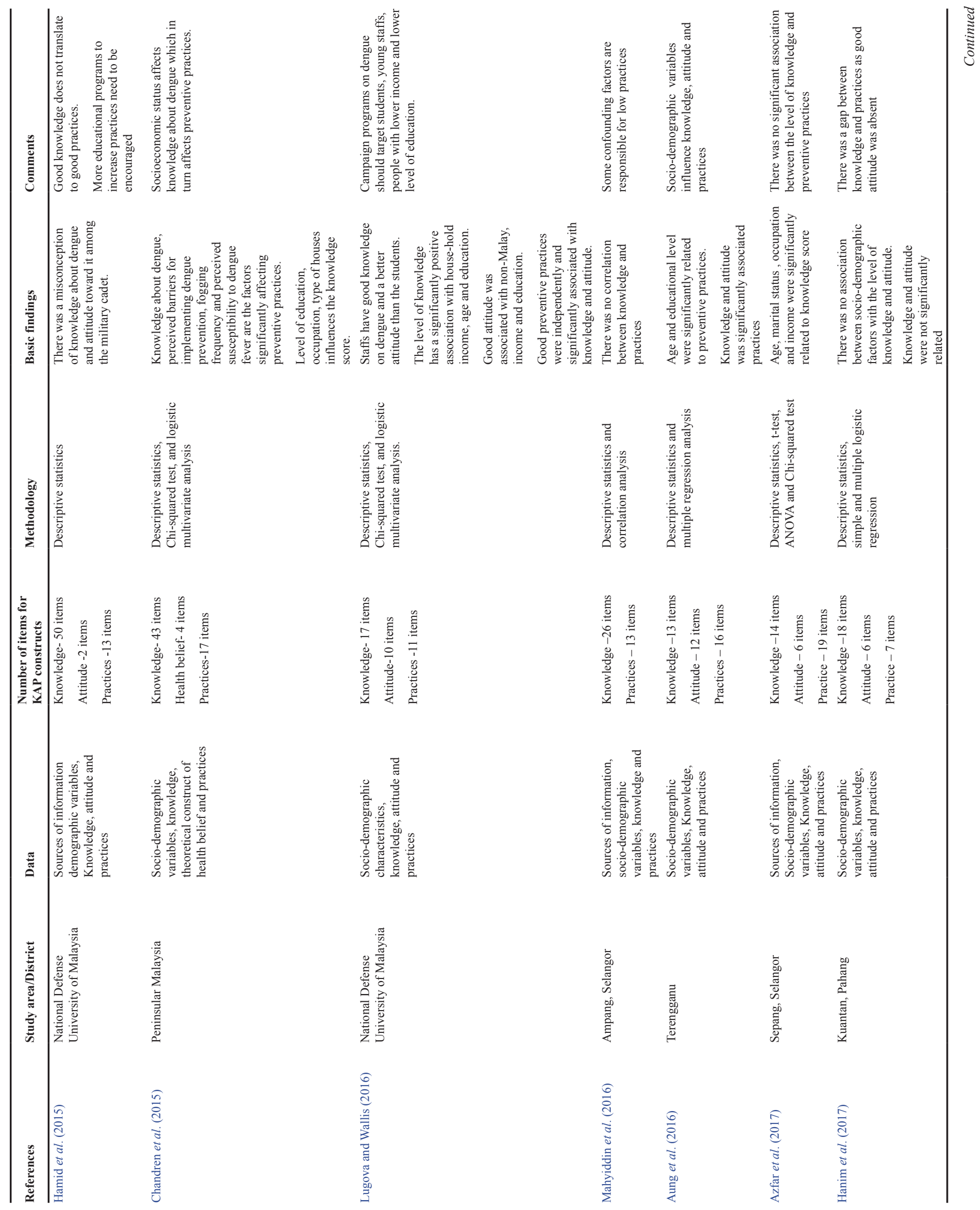


methods to achieve the objectives of their studies at varying degrees. Some of the studies only consider knowledge and practices (Mahyiddin et al., 2016; Naing et al., 2011) but knowledge about DF was differentiated from knowledge about Aedes mosquitoes, while some studies joined the construct of attitude and practices together as a single entity (Ayyamani et al., 1986). Among some of the studies, practices were used as the dependent variables, while socio-demographic variables and knowledge were the independent variables (Naing et al., 2011). The data collected by Lugova and Wallis (2016) were found to be negatively skewed after the test of normality, so interquartile range was used for the data description. Five of the studies used logistic regression models to analyze the data collected. Table 2 shows the summary of the analytical approaches used by different authors.

\section{Correlation}

Hairi et al. (2003) used correlation analysis to examine the association between socio-demographic characteristics and KAP regarding dengue in four villages of Kuala Kangsar of state of Perak in June 2002. The result from the study showed that the socio-demographic variables were not significantly associated with knowledge, attitude, and practices but cross tabulation showed that there was a significant association between knowledge and attitude but no significant association between knowledge and practices. Furthermore, there was no significant association between attitude and practices. Rozita et al. (2006) also used correlation analysis to observe the relationship between knowledge and practice; knowledge and attitude; attitude and practice in a study conducted in Kampung Datok Keramat, Kuala Lumpur. The results showed that there was a weak positive relationship between knowledge and practice but there was no significant relationship between knowledge and attitude; attitude and practices. Another KAP study conducted by Mahyiddin et al. (2016) among the residents living in a low-cost flat, Pandan Indah Ampang, Selangor also used correlation analysis to examine the relationship between knowledge score on dengue and preventive practices score. The result showed that there was no correlation between knowledge and practices of the respondents.

\section{Student's t-test}

Rozita et al. (2006) used Student's $t$-test to compare mean scores of knowledge, attitude, and practices between gender (male and female), ownership of house (owned and rent), education (no formal education and secondary/tertiary), and dengue history (yes and no) of respondents in Kampung Datok Keramat, Kuala Lumpur. The results of the study showed that there was a significant difference between the mean score of knowledge of those who had dengue history compared to those who never had DF in the past. The mean score of knowledge and attitude of those who had a formal education was significantly different from those without formal education. Gender of the respondents also showed a significant difference as the female respondents had a better attitude than the male respondents. Finally, there was a statistically significant difference between the preventive practices of the respondents who were financially buoyant enough to own a house and those who rented houses. Al-Zurfi et al. (2015) used a $t$-test to reveal the difference in knowledge score of some students of Alam Shah Science School, Cheras before and 
Table 2. References and analytical approaches.

\begin{tabular}{|c|c|c|c|c|c|c|c|}
\hline References & $\begin{array}{c}\text { Descriptive } \\
\text { statistics }\end{array}$ & $\begin{array}{c}\text { Correlation } \\
\text { Analysis }\end{array}$ & $\begin{array}{c}\text { Student's } \\
t \text {-test }\end{array}$ & ANOVA & $\begin{array}{c}\text { Chi-squared } \\
\text { test }\end{array}$ & $\begin{array}{c}\text { Regression } \\
\text { Analysis }\end{array}$ & $\begin{array}{c}\text { Logistic } \\
\text { regression }\end{array}$ \\
\hline Ayyamani et al. (1986) & $\checkmark$ & & & & & & \\
\hline Hairi et al. (2003) & $\checkmark$ & $\checkmark$ & & & $\checkmark$ & & \\
\hline Rozita et al. (2006) & $\checkmark$ & $\checkmark$ & $\checkmark$ & $\checkmark$ & & & \\
\hline Naing et al. (2011) & $\checkmark$ & & $\checkmark$ & & $\checkmark$ & $\checkmark$ & \\
\hline Al-Dubai et al. (2013) & $\checkmark$ & & $\checkmark$ & $\checkmark$ & $\checkmark$ & & \\
\hline Leong (2014) & $\checkmark$ & & & & $\checkmark$ & & $\checkmark$ \\
\hline Al-Zurfi et al. (2015) & $\checkmark$ & & $\checkmark$ & & & & $\checkmark$ \\
\hline Hamid et al. (2015) & $\checkmark$ & & & & & & \\
\hline Chandren et al. (2015) & $\checkmark$ & & & & $\checkmark$ & & $\checkmark$ \\
\hline Lugova and Wallis (2016) & $\checkmark$ & & & & $\checkmark$ & $\checkmark$ & $\checkmark$ \\
\hline Mahyiddin et al. (2016) & $\checkmark$ & $\checkmark$ & & & & & \\
\hline Aung et al. (2016) & $\checkmark$ & & & & & $\checkmark$ & \\
\hline Azfar et al. (2017) & $\checkmark$ & & $\checkmark$ & $\checkmark$ & $\checkmark$ & & \\
\hline Hanim et al. (2017) & $\checkmark$ & & & & & & $\checkmark$ \\
\hline Firdous et al. (2017) & $\checkmark$ & & & & $\checkmark$ & & \\
\hline Yussof et al. (2017) & $\checkmark$ & & & & & $\checkmark$ & \\
\hline Kamel et al. (2017) & $\checkmark$ & & & & $\checkmark$ & & \\
\hline
\end{tabular}

after an interventional Correlation Analysis education program. The conclusion of the study was that the knowledge score of students increased after the health education program. Azfar et al. (2017) in a study conducted in the semi-urban community of Sepang, Selangor used a $t$-test to show that there was a significant difference between the level of knowledge of married and single, government workers and unemployed, the respondent with higher income and lower income.

\section{Analysis of variance (ANOVA)}

Rozita et al. (2006) used analysis of variance (ANOVA) to test the difference of knowledge, attitude, and practice among the three different locations in Kampung Datok Keramat, Kuala Lumpur, the findings revealed that the mean practice score of the locations showed a significant difference, while the knowledge and attitude of the locations show no significant difference, this implies that preventive practices against DF are different from one location to another. An ANOVA done by Azfar et al. (2017) has shown that age group is a significant factor affecting the level of knowledge.

\section{Chi-Squared test}

A KAP study regarding dengue carried out in Seremban district, Malaysia by Naing et al. (2011) showed that there was a significant association between knowledge score of dengue and age, educational level, marital status, and occupation. Practice score was significantly associated with age, educational level, and knowledge score of dengue. Al-Dubai et al. (2013) used chisquare to establish that there was an association between some of the socio-demographic variables and knowledge of dengue; age and ethnicity were significantly associated with knowledge, knowledge was significantly associated with attitude and practices, attitude was significantly associated with educational and occupational status, while practices were significantly associated with age, marital status, geographical area, and knowledge. Leong (2014) also used cross tabulation and chisquare to show that knowledge and attitude are related variables but there was no significant association between knowledge and practice; attitude and practices. Chandren et al. (2015) conducted a study among 16 randomly selected Orang Asli villages from eight states in Peninsular Malaysia; chi-square was used to show that living condition, type of house, occupation, and average monthly income were associated with knowledge on dengue. Lugova and Wallis (2016) used chi-square to evaluate the difference between the level of KAP regarding dengue among students and staff in National Defense University of Malaysia, Kuala Lumpur. The result revealed that staff have better KAP regarding dengue than students. Chi-square analysis of the study conducted in Sepang, Selangor revealed that there exist no association between the level of knowledge and preventive practices against dengue (Azfar et al., 2017). Firdous et al. (2017) used categorical analysis and chi-square test to examine the significant relationship between socio-demographic factors and KAP regarding dengue in a study conducted in Dewan, Bandaraya, Ipoh community. The results showed that there was no significant association between sociodemographic factors and knowledge but there was a significant association between socio-demographic factors and attitude and there was also a significant association between sociodemographic factors and practices, most importantly the level of education influences high preventive practices. Kamel et al. (2017) evaluated the association between knowledge, attitude, and practice in a study conducted in the community of Taman Salak Baiduri Sepang, Selangor with the use of cross-tabulation and chisquare. The result showed that there was a significant association between knowledge and attitude, while there was no significant association between attitude and practices.

\section{Regression Analysis}

Mean score on practices on dengue was used as the dependent variable; a stepwise method of elimination was applied to discover the non-significant variables and the multivariate regression analysis indicated that only knowledge on dengue was positively significant with preventive practices (Naing et al., 2011). Aung et al. (2016) in a study conducted among a rural 
population of Terengganu, Malaysia used multiple regression models to reveal the factors associated with preventive practices against dengue to be age, level of education, knowledge, and attitude. In a regression analysis, Lugova and Wallis (2016) showed that knowledge on dengue and attitude towards dengue was significantly associated with preventive practices on dengue. A KAP study on dengue was conducted by Yussof et al. (2017) in a dengue hot spot area in Universiti Sultan Zainal Abidin (UniSZA) Terengganu among students, multiple regression model was used to evaluate significant factors associated with preventive practices against dengue. Socio-demographic factors such as age, level of education, marital status, geographical areas, and duration of living in the survey area were factors revealed to be influencing practices against dengue. After the adjustment for confounding variables, knowledge and attitude are significantly related to preventive practices and the simple regression analysis result also showed that practice score and knowledge score are significantly related.

\section{Logistic regression}

Logistic regression has been extensively applied to KAP regarding dengue studies to discover the most influencing independent variable of preventive practice. With logistic regression, Leong (2014) was able to establish that knowledge was related with age, ethnicity, and educational level; and attitude was related with ethnicity and educational status, while practices were associated with ethnicity and marital status in a study carried out in Rembau and Bukit Pelanduk, Sembilan. Al-Zurfi et al. (2015) used simple logistic regression to assess the association of knowledge and race; knowledge and socioeconomic status; knowledge and residential areas. The result from the study showed that there was no significant association between knowledge and all the socio-demographic factors. Chandren et al. (2015) used a multivariate logistic regression model to reveal the factors that were mostly affecting preventive practices of dengue among Orang Asli in Peninsular Malaysia to be knowledge on dengue, perceived barrier, the frequency of fogging, and perceived susceptibility. Lugova and Wallis (2016) used a logistic regression model to examine the factors independently affecting preventive practices, the results showed that knowledge and attitude are independently associated with good preventive practices. Hanim et al. (2017) conducted a KAP regarding dengue study among adult residents of Felda Sungai Pancing Timur, Kuantan, Pahang, multiple logistic regression analysis was used to show that socio-demographic factors have no influence on the level of knowledge and attitude towards dengue. Simple logistic regression was also used to show that there was no association between knowledge score of dengue and attitude score of the respondents.

\section{Questionnaire, scoring method, and categorization of the latent constructs}

Hairi et al. (2003) assessed knowledge with 14 items, attitude with 13 items, and practices with 9 items. The composite scoring system was used and categorization of knowledge, attitude, and practices as regard dengue was done into two basic levels; good and poor with an arbitrary cut-off. Rozita et al. (2006) categorized knowledge, attitude, and practices on dengue into "good" and "moderate to poor" with an arbitrary cut-off of $75 \%$ of each score of the construct of KAP. The correct answer was given a point and summed for each construct. The items used for measuring the construct were not detailed in the article. The questionnaire used by Naing et al. (2011) measured the construct of knowledge about DF with 14 items and construct of knowledge about Aedes mosquitoes with three items, while practices were measured with 10 items. A composite scoring method was used. A good knowledge about dengue was categorized based on scores ranging from 10 to 14, a good knowledge of Aedes mosquitoes: score of 2 and 3, good practices: scores ranging from 5 to 10 and otherwise. In the study carried out by Al-Dubai et al. (2013), knowledge was measured with 15 items, the attitude was measured with 6 items, and practice was measured with 11 items. The global composite scoring method was used to code the right answer to be 1 and wrong answer to be 0 . The median score of knowledge was used as a scale to categorize the construct into two groups; knowledgeable and non-knowledgable. Scores greater than 11 were categorized as knowledgeable and knowledge scores $\leq 11$ were categorized as non-knowledgable. Leong (2014) used a questionnaire that measures knowledge with 10 items, attitude with 6 items, and practices with 7 items. Leong also made use of the global composite scoring method by coding each correct answer as 1 and wrong answer as 0 . Knowledge score $\geq 7$ was categorized as good knowledge and otherwise; attitude score $\geq 4$ was categorized as good attitude; practices score $\geq 4$ was categorized as good practices and otherwise. Al-Zurfi et al. (2015) measured knowledge with 15 items, attitude with 10 items, and practices with 11 items. Coded the correct answer as 1 and 0 for the wrong answer to obtain each score for knowledge, attitude, and practices. Categorization into good knowledge, good attitude, and good practices were done by an arbitrary cut-off score $\geq 12$, $\geq 8$, and $\geq 6$, respectively. The scores less than the arbitrary cut-off were categorized as moderate and poor.

Knowledge and awareness of dengue were measured with 50 items, attitude with 2 items, and practices with 13 items. No arbitrary cut-off for categorization of the constructs and no scoring method were used in their analysis (Hamid et al., 2015). The results and conclusions were based on descriptive statistics.

An improved shift from the construct of attitude to health belief model (HBM) by Chandren et al. (2015) with knowledge of dengue and preventive practices gave the KAP regarding dengue study a distinguished approach. Knowledge of dengue was measured with 43 items, HBM has four different sub-construct, such as perceived severity, perceived susceptibility, perceived barrier and self-efficacy, and cue to action. The first three subconstructs were measured on 1-10 point scale, self-efficacy was measured on two point scale while cueing to action (density of the mosquitoes in the neighborhood) was also measured with 1-4 point scale based on respondent's discretion and finally, preventive practices were measured with 17 items.

Lugova and Wallis (2016) used 17 items to evaluate knowledge on dengue, 10 items for attitude towards dengue, and 11 items for preventive practices. For knowledge, the correct answer was coded 1, incorrect and "not sure" options were coded as 0 . Five-point scales were used to measure attitude ranging from 0 to 4 . Practices options were either yes or no, yes was coded as 1 and no as 0 . Knowledge, attitude, and practices were categorized 
into two different levels; good and moderate to poor. Scores $>75 \%$ were considered as good and scores $<75 \%$ was considered to be "moderate to poor." Mahyiddin et al. (2016) used 26 items to measure knowledge and 13 items to measure practices, the questionnaire was adapted from Yboa and Labrague (2013). The correct answers were coded as 1 and the wrong answers as 0 . Arbitrary cut off was used as a standard to categorize knowledge into five different levels; $0-5$ as poor knowledge, 6-10 as fair knowledge, 11-15 as moderate knowledge, 16-20 as good knowledge, and 21-26 as excellent knowledge. Preventive practices were also categorized into five different levels; not at all (1-1.50), limited extent (1.51-2.50), moderately extent $(2.51-$ $3.50)$, great extent (3.51-4.50), and very great extent (4.51-5.00). Aung et al. (2016) used 13 items to measure knowledge; 12 items to measure attitude, and 16 items to measure practices. The knowledge score was categorized into three different levels; high knowledge (129-108), moderate knowledge (107-86), and low knowledge (85-43) by summing the rating scale. Fivepoint scales were employed to measure attitude which was also categorized into three different levels; good attitude (60-48), neutral attitude (47-36), and poor attitude (35-12). Practice score was categorized into two levels; good practice (32-24) and poor practices (23-16).

Azfar et al. (2017) used 14 items to assess knowledge, 6 items to assess attitude, and 10 items to assess practices. For the knowledge, the correct answer was coded as 1 and the wrong answer as 0 . Bloom's cut off point was used to categorize knowledge score into three different levels; high knowledge (1214), moderate knowledge (9-11), and low knowledge (0-8) which was an adapted method from Ahmed and Taneepanichskul (2008). Practice score was also categorized into three different levels, namely limited practice, moderate practice, and extensive practice using the Bloom's cut-off and summation of the rating scale. In the KAP study done by Firdous et al. (2017), the items used to measure knowledge, attitude, and practices were not specified. The scoring method was also not declared but the categorization of the construct was done base on three levels; low, medium, and high. Yussof et al. (2017) evaluated knowledge with 13 items, attitude with 12 items, and practices with 16 items. Reverse score rating was used to categorized knowledge score into three different levels; high knowledge (0-21), moderate knowledge (21-43), and low knowledge (44-86) by coding the correct answer as 0 , wrong answer as 1 , and "don't know" as 2 . Attitude score was categorized into two levels with a summation of the rating scale; good attitude (48-60) and bad attitude (36-47) and practices score was also categorized into two levels by summing of the rating scale; good practice (32-48) and bad practice (16-31).

Kamel et al. (2017) used 10 items to assess knowledge, 6 items to assess attitude, and 10 items to assess practices. The correct answer was coded as 1 and the wrong answer as 0 . Knowledge score, attitude score, and practice score were all categorized into two different levels with the median score as the scale; good knowledge and practices (7-10), poor knowledge and practices (0-6), good attitude (3-6), and poor attitude (0-2). Hanim et al. (2017) evaluated knowledge with 18 items, attitude with 6 items, and practices with 7 items. Categorization into two levels (good and poor) was done using mean cut-off point.

\section{Risk of bias of the selected articles}

CASP (2014) checklist for the qualitative study consists of 10 items. Number 6 of the checklist was modified to conform to the feature of evaluating studies involving self-administered questionnaires. Virtually, all the studies considered had a low risk of bias from number 1 to 5 of the checklist, except for two articles (Aung et al., 2016; Yussof et al., 2017) which only explained the importance of KAP studies regarding dengue without clearly stating the goal of the study. Out of the 17 literature reviewed, only six of the literatures gave importance to construct validity and reliability of the questionnaire which makes them a low risk of bias in terms of instrument used for the study. Seven of the literatures were unclear of the potential bias because of the results of the questionnaires were only presented in the article while the remaining four articles did not give consideration to content validity and reliability of the questionnaires used for the study. On ethical issues, seven of the studies stated the ethical clearance for studies while 10 of literatures had a high risk of bias based on ethical considerations because there was no clear statement of ethical clearance in the articles. Fifteen of the reviewed literatures had a low risk of bias on the intensity of the data analysis. Ayyamani et al. (1986) and Hamid et al. (2015) used only descriptive statistics to present result without any statistical test of significance. Finally, in terms of clear statements of findings of the study, contribution and value of the research to the society, all the literature considered had a low risk of bias. Table 3 shows the summary of the risk of bias of the literature considered.

\section{DISCUSSION}

With upward trend of dengue infection in Malaysia for more than a decade (2000-2015; 7,103 cases to 120,836 cases) and the downward trend experienced from 2015 to 2017 (120,836-82,840 cases), Malaysia still needs to increase effort on more health campaign programs to educate the populace about prevention of dengue infection. Human behaviors are known to play a significant role in the continuing existence of dengue vectors and transmission of the virus (Higa, 2011) because dengue vectors depend on the human environment to feed and reproduce. Study from other country had also confirmed that higher level of education influences better chance of awareness and preventive measure against dengue vectors (Dhimal et al., 2014) in Nepal, this implies that there should be more focus on people with low socioeconomic status because people with higher economic status are less likely to be infected by dengue due to their choice of living environment and condition (Mondini and Chiaravalloti Neto, 2007). All the reviewed articles recommended that effective dengue prevention and control programs need to be put in place to curtail the spread of the viral infection.

\section{Strength and limitation of studies}

Various statistical analytical approaches have been used to determine the KAP on dengue among different sets of people in different locations and the possible influence of sociodemographic factors on KAP regarding dengue in Malaysia (Table 2). No predictive model has been formulated on KAP regarding dengue studies. In general, an appropriate sampling procedure and the large sample size of data will increase the 


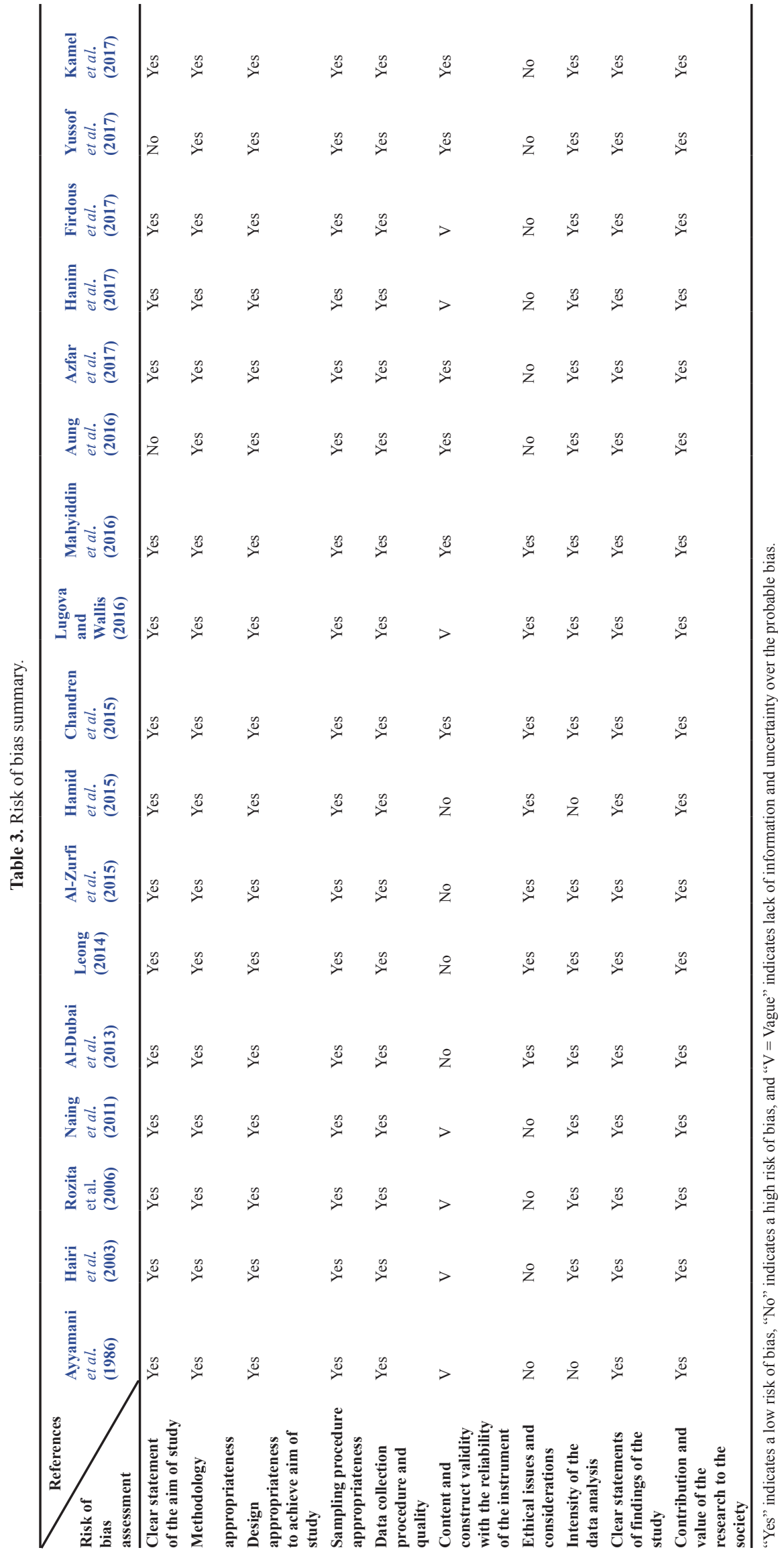


precisions of results. The variability of questionnaires, scoring method, sample size, arbitrary cut-offs restricts results from one study to another from being generalized. Reliability, content, and construct validity of the questionnaire should be carefully examined appropriately.

\section{CONCLUSION}

Clear evidence which showed that socio-demographic variables influence KAP regarding dengue has been proven. It is important to harmonize and validate the content of all the structured questionnaires in order to reduce the variability of results based on the questionnaire used for data collection. Finally, integration of qualitative and quantitative modeling approach to KAP studies can aid in projecting the impact of socio-demographic factors on future KAP regarding dengue studies.

\section{ACKNOWLEDGMENT}

Ministry of Higher Education under the Fundamental Research Grant Scheme (FRGS) (Project No: 02-02-14-1561 FR) and we appreciate everybody who contributed to the success of this study.

\section{REFERENCES}

Ahmed N, Taneepanichskul S. Knowledge, attitude and practices of dengue fever prevention among people in Males', Maldives. J Health Res, 2008; 22:33-7.

Al-Dubai SA, Ganasegeran K, Mohanad Rahman A, Alshagga MA, Saif-Ali R. Factors affecting dengue fever knowledge, attitudes and practices among selected urban, semi-urban and rural communities in Malaysia. Southeast Asian J Trop Med Public Health, 2013; 44(1): $37-49$.

Al-Zurfi BM, Fuad MD, Abdelqader MA, Baobaid MF, Elnajeh M, Ghazi HF, Ibrahim MH, Abdullah MR. Knowledge, attitude and practice of dengue fever and health education programme among students of Alam Shah science school, Cheras, Malaysia. Malaysian Journal of Public Health Med, 2015; 129:63-2.

Aung MM, Hassan AB, Kadarman NB, Hussin TM, Barman A, Ismail SB, Hashim SE. Knowledge, attitude, practices related to dengue fever among rural population in Terengganu, Malaysia. Malaysian J Public Health Med, 2016; 16(2):15-23.

Ayyamani UD, Ying GC, San OG. A knowledge atitude and practice (KAP) study on dengue/dengue haemorrhagic fever and the Aedes mosquitoes. Med J Malaysia, 1986; 41(2):108-15.

Azami NA, Salleh SA, Neoh HM, Zakaria SZ, Jamal R. Dengue epidemic in Malaysia: Not a predominantly urban disease anymore. BMC Res Notes, 2011; 4(1):216.

Azfar M, Omarulharis S, Azfar H, Maryam A, Hafizah S, Adibah BA, Akmal N. Knowledge, attitude and practice of dengue prevention among sub urban community in Sepang, Selangor. Int J Public Health Clin Sci, 2017; 4(2):73-83.

Benthem VBH, Khantikul N, Panart K, Kessels PJ, Somboon P, Oskam L. Knowledge and use of prevention measures related to dengue in northern Thailand. Trop Med Int Health, 2002; 7(11):993-1000.

Chandren JR, Wong LP, AbuBakar S. Practices of dengue fever prevention and the associated factors among the Orang Asli in Peninsular Malaysia. PLoS Negl Trop Dis, 2015; 9(8):e0003954.

Critical Appraisal Skills Programme. CASP checklists. Critical Appraisal Skills Programme (CASP): Making sense of evidence. 2014.

Dhimal M, Aryal KK, Dhimal ML, Gautam I, Singh SP, Bhusal CL, Kuch U. Knowledge, attitude and practice regarding dengue fever among the healthy population of highland and lowland communities in Central Nepal. PLoS One, 2014; 9(7):e102028.
Dobbins JG, Else JG. Knowledge, attitudes, and practices related to control of Dengue haemorrhagic fever in an urban Malay kampung. Southeast Asian J Trop Med Public Health, 1975; 6(1):120-6.

Ewing DA, Cobbold CA, Purse BV, Nunn MA, White SM. Modelling the effect of temperature on the seasonal population dynamics of temperate mosquitoes. J Theor Biol, 2016; 400:65-79.

Firdous J, Mohamed A, Al Amin M, Ihsan M, Faris'Imadi M, Hakim MK, Afiq M, Muhamad N. Knowledge, attitude and practice regarding dengue infection among Ipoh Community, Malaysia. J App Pharm Sci, 2017; 7(08):099-103.

Gubler DJ. Dengue, urbanization and globalization: the unholy trinity of the 21st century. Trop Med Health, 2011; 39(Suppl 4):S3-11.

Gubler DJ, Reiter P, Ebi KL, Yap W, Nasci R, Patz JA. Climate variability and change in the United States: potential impacts on vectorand rodent-borne diseases. Environ Health Perspect, 2001; 109(Suppl 2): $223-33$.

Hairi F, Ong CH, Suhaimi A, Tsung TW, bin Anis Ahmad MA, Sundaraj C, Soe MM. A knowledge, attitude and practices (KAP) study on dengue among selected rural Communities in the Kuala Kangsar district. Asia Pacific J Public Health, 2003; 37-43.

Hamid M, Lugova H, Mon A, Knight V. Awareness and practice related to dengue infection among military cadets in Malaysia. J Behav Health, 2015; 4(2):1.

Hanim AA, Razman MR, Jamalludin AR, Nasreen EH, Phyu HM, SweSwe L, Hafizah P. Knowledge, attitude and practice on dengue among adult population in Felda Sungai Pancing Timur, Kuantan, Pahang. Int Med J Malaysia, 2017; 16(2).

Higa Y. Dengue vectors and their spatial distribution. Trop Med Health, 2011; 39(4SUPPLEMENT):S17-27.

Kamel MN, Gnanakkan BD, Fauzi FZ, Hanafi MI, Selvarajah G, Jabar SA, Hamid SA. The KAP study on dengue among community in Taman Salak Baiduri, Sepang, Selangor. Int J Sci Healthcare Res, 2017; $18: 19-25$

Lam SK. Two decades of dengue in Malaysia. Trop Med, 1994, 35(4):195-200.

Leong TK. Knowledge, attitude and practice on dengue among rural communities in Rembau and Bukit Pelanduk, Negeri Sembilan, Malaysia. Int J Trop Dis Health, 2014; 4(7):841-8.

Lugova H, Wallis S. Cross-sectional survey on the dengue knowledge, attitudes and preventive practices among students and staff of a public university in Malaysia. J Comm Health, 2017; 42(2):413-20.

Mahyiddin NS, Mohamed R, Mohamed HJJ, Ramly N. High knowledge on dengue but low preventive practices among residents in a low cost flat in Ampang, Selangor. Malaysian J Nurs, 2016; 8(1).

Marinho RA, Beserra EB, Bezerra-Gusmão MA, Porto VD, Olinda RA, dos Santos CA. Effects of temperature on the life cycle, expansion, and dispersion of Aedes aegypti (Diptera: Culicidae) in three cities in Paraiba, Brazil. J Vector Ecol, 2016; 41(1):1-10.

Moher D, Liberati A, Tetzlaff J, Altman DG, Prisma T. Preferred reporting items for systematic reviews and meta-analyses: the PRISMA statement. Int J Surg, 2010; 8(5):336-41.

Mondini A, Chiaravalloti Neto F. Socioeconomic variables and dengue transmission. Rev Saúde Pública, 2007; 41(6):923-30.

Mudin RN. Dengue incidence and the prevention and control program in Malaysia. Int Med J Malaysia, 2015:14(1):5-10.

Naing C, Ren WY, Man CY, Fern KP, Qiqi C, Ning CN, Ee CW. Awareness of dengue and practice of dengue control among the semi-urban community: a cross sectional survey. J Comm Health, 2011; 36(6):1044-9.

Naish S, Dale P, Mackenzie JS, McBride J, Mengersen K, Tong S. Climate change and dengue: a critical and systematic review of quantitative modelling approaches. BMC Infect Dis, 2014; 14(1):167.

Poovaneswari S. Dengue situation in Malaysia. Malaysian J Pathol, 1993; 15(1):3-7.

Rothman AL. Immunity to dengue virus: a tale of original antigenic sin and tropical cytokine storms. Nat Publishing Group, 2011; 11(8):532-43. 
Rudnick A. Studies of the ecology of dengue in Malaysia: a preliminary report. J Med Entomol, 1965; 2(2):203-8.

Rozita WM, Yap BW, Veronica S, Muhammad AK, Lim KH, Sumarni MG. Knowledge, attitude and practice (KAP) survey on dengue fever in an urban Malay residential area in Kuala Lumpur. Malays J Public Health Med, 2006; 6(2):62-7.

Yboa BC, Labrague LJ. Dengue knowledge and preventive practices among rural residents in Samar province, Philippines. Am J Public Health Res, 2013; 1(2):47-52.

Yussof FM, Hassan A, Zin T, Hussin TM, Kadarman N, Umar R. Knowledge of dengue among students in Universiti Sultan Zainal Abidin (UNISZA), Terengganu, Malaysia and the influence of knowledge of dengue on attitude and practice. J Fundamental Appl Sci, 2017; 9(2S): 199-216.

How to cite this article:

Lamidi-Sarumoh AA, Shohaimi S, Adam MB, Hisham MN, Oguntade ES. Systematic review of knowledge, attitude, and practices regarding dengue in Malaysia. J App Pharm Sci, 2018; 8(12): 080-091 